\title{
Global efforts in conquering lung cancer in China
}

Li Yan ${ }^{1,2^{*}}$ and Li Xu ${ }^{3^{*}}$

\begin{abstract}
Lung cancer, the most prevalent and deadly malignancy in the world, poses a particularly critical healthcare challenge to China due to the rapidly increasing new cases and the unique cancer genetics in Chinese patient population. Substantial progress has been made in molecular diagnosis and personalized treatment of the disease. The field is now moving towards multiple new directions to include (1) new generation of targeted agents such as epidermal growth factor receptor and anaplastic lymphoma kinase inhibitors to overcome resistance to their early generation counterparts; and (2) deeper understanding of tumor genetics of each individual patient and consequently the application of biomarkers to guide personalized treatment as well as novel drug development including combination therapy. The increasing capacity in innovative cancer drug research and development is supported by extensive collaboration within China and globally, and across academia and industry, to build up expertise and infrastructure in early-phase clinical testing of novel drugs. With these combined efforts, new and better medicines will be available for lung cancer patients in China in the near future.
\end{abstract}

Keywords: Lung cancer, Targeted agents, Biomarker, Personalized medicine, Healthcare in China

Lung cancer, the most prevalent and deadly malignancy, accounts for a staggering 1.6 million new cases diagnosed every year and approximately $21 \%$ of cancer deaths to the global cancer burden [1]. In China, lung cancer has become a particularly challenging disease because of air pollution and smoking with an estimated 733,280 new cases every year and 671,625 cancer-related deaths [25]. In this special issue of the Chinese Journal of Cancer $(C J C)$, we have organized a series of articles reviewing the global collaborative effort in improving lung cancer treatment in China.

Lung cancer treatment in China has shown substantial advancements in recent years exemplified by the integration of targeted therapies in standard of care. In the landmark Iressa Pan-ASia Study (IPASS) study, gefitinib (Iressa), a mutated epidermal growth factor receptor $(E G F R)$ inhibitor, demonstrated superiority to carboplatin and paclitaxel in treating patients with lung cancer

\footnotetext{
*Correspondence: ynyinternational@yahoo.com; li2xu@hotmail.com

${ }^{1}$ The US Chinese Anti-Cancer Association, Martinez, CA 94553, USA

3 Jiangsu Hengrui Medicine Co., LTD, 778 Dong Fang Road, 12 F, Pudong,

Shanghai 200122, P. R. China

Full list of author information is available at the end of the article
}

in East Asia [6]. A follow-up study confirmed that EGFR mutation is the strongest predictive biomarker for progression-free survival and tumor response to first-line gefitinib versus carboplatin and paclitaxel [7]. Similarly, crizotinib (Xalkori), an anaplastic lymphoma kinase $(A L K)$ inhibitor, has shown superiority compared with chemotherapy in lung cancer patients with $A L K$ translocation [8]. The high prevalence of activating EGFR mutations (32.7\%) and $A L K$ rearrangements (6.8\%) among lung cancer patients in China has further expanded the use of these targeted agents [9]. However, the enthusiasm in using these targeted agents also brought up new challenges in clinical practice including the debate of whether such agents can and should be used in patients with wildtype targets as reviewed by Zhou et al. [10]. The review provides an important perspective in the context of relatively scarce healthcare resources and the heterogeneous diagnostic approaches in China.

Despite the encouraging clinical efficacy delivered by targeted agents, these monotherapies benefit only small subsets of patients with oncogene-driven tumors and, further, virtually all develop resistance and succumb to relapsed diseases [11]. Depending on the mechanisms 
of resistance, patients with relapsed diseases may further benefit from (1) new generation of targeted agents designed to address the resistance mechanisms; and (2) combination therapy to target multiple pathways simultaneously including resistance mechanisms.

The article by $\mathrm{Xu}$ [12] describes the discovery and development of avitinib, an investigational third-generation EGFR inhibitor originally discovered in China, and is being developed in China and the United States (US). Similar to other third-generation EGFR inhibitors such as AZD9291 and CO1686, avitinib irreversibly inhibits the mutant EGFR, spares the wild-type EGFR thus avoiding or minimizing normal tissue toxicities, and overcomes T790M mutation-mediated resistance to early-generation EGFR inhibitors. The ongoing phase 1 study of avitinib in China in lung cancer patients with T790M mutation will provide the first set of clinical data of thirdgeneration EGFR inhibitors in Chinese patients. The parallel clinical development in the US as an integrated global development strategy will generate data in relevant patient population in which other third-generation EGFR inhibitors are being investigated. It is highly expected that avitinib, an innovative drug discovered in China, has the potential to become the first-in-class new generation EGFR inhibitor in China.

The successful clinical approach to effectively treating lung cancer and addressing drug-resistance relies on the use of biomarkers to personalize cancer treatment. The review article by Fang et al. [13] from MD Anderson Cancer Center discusses predictive biomarkers not only for traditional targeted agents such as inhibitors of EGFR, ALK, and c-ros oncogene 1 receptor tyrosine kinase (ROS1) but also for immune checkpoint inhibitors. The article also highlights the need for identifying predictive biomarkers in anticancer drug development. To succeed in such biomarker-based drug development approach, a mature network of clinical trial sites with sound translational medicine capability is a prerequisite. Yang et al. [14] analyzed early-phase clinical trials in lung cancer in the US and conducted a comparison with the trials conducted by the Chinese Thoracic Oncology Group (CTONG), the first and largest thoracic oncology corporative group in China. The high percentage of earlyphase clinical trials in the US provides a solid foundation for identifying, developing, and validating biomarkers to expedite drug development in late phases. In contrast, CTONG has yet to conduct a single early-phase clinical trial since its inception in 2007 at the time of the analysis. Part of the reasons for this discrepancy between the US and China resides in the lack of clinical trial staff, e.g., physicians and nurses, with experience in early-phase oncology trials. To address this gap, the US Chinese AntiCancer Association (USCACA), with generous support from Jiangsu Hengrui Medicine Co., LTD, has initiated the Early Phase Oncology Research Training (EFFORT) Program [15]. The scholarship will support training of young investigators from China in collaboration with US cancer centers and National Cancer Institute. Through short rotation programs, Chinese young investigators will gain experience in designing and conducting earlyphase oncology clinical trials and bring the best practice to their home institutes in China [14].

We firmly believe that the advancement in our understanding in genetics underlying lung cancer, the rapidly growing innovative drug research and development (R\&D) capacity, the enhanced global collaboration, and the expanding capability in cancer drug clinical development will lead to the next wave of breakthroughs in the treatment of lung cancer in a personalized fashion in China.

\section{Authors' contribution}

$L Y$ and $L X$ drafted the manuscript. Both authors read and approved the final manuscript.

\section{Author details}

${ }^{1}$ The US Chinese Anti-Cancer Association, Martinez, CA 94553, USA. ${ }^{2}$ Beijing Cancer Hospital and Institute, Peking University School of Oncology, Beijing 100142, P. R. China. ${ }^{3}$ Jiangsu Hengrui Medicine Co., LTD, 778 Dong Fang Road, 12 F, Pudong, Shanghai 200122, P. R. China.

\section{Compliance with ethical guidelines}

Competing interests

Li Yan is an employee of GSK. Li Yan reports no other conflict of interest.

Received: 4 June 2015 Accepted: 5 June 2015

Published online: 28 July 2015

\section{References}

1. International Agency for Research on Cancer. GLOBOCAN 2012: estimated cancer incidence, mortality and prevalence worldwide in 2012 World Health Organization. 2012. Available at: http://globocan.iarc.fr/ Pages/fact_sheets_cancer.aspx.

2. Zhang W, Qian CN, Zeng YX. Air pollution: a smoking gun for cancer. Chin J Cancer. 2014;33:173-5.

3. Huang YB, Song FJ, Liu Q, Li WQ, Zhang W, Chen KX. A bird's eye view of the air pollution-cancer link in China. Chin J Cancer. 2014;33:176-88.

4. Loomis D, Huang W, Chen G. The International Agency for Research on Cancer (IARC) evaluation of the carcinogenicity of outdoor air pollution: focus on China. Chin J Cancer. 2014;33:189-96.

5. Li YG, Gao X. Epidemiologic studies of particulate matter and lung cancer. Chin J Cancer. 2014;33:376-80

6. MokTS, Wu YL, Thongprasert S, Yang CH, Chu DT, Saijo N et al. Gefitinib or carboplatin-paclitaxel in pulmonary adenocarcinoma. N Engl J Med. 2009:361:947-57.

7. Fukuoka M, Wu YL, Thongprasert S, Sunpaweravong P, Leong SS, Sriuranpong $\vee$ et al. Biomarker analyses and final overall survival results from a phase III, randomized, open-label, first-line study of gefitinib versus carboplatin/paclitaxel in clinically selected patients with advanced nonsmall-cell lung cancer in Asia (IPASS). J Clin Oncol. 2011;29:2866-74.

8. Solomon BJ, Mok T, Kim DW, Wu YL, Nakagawa K, Tarek Mekhail T et al. PROFILE 1014 Investigators. First-line crizotinib versus chemotherapy in ALK-positive lung cancer. N Engl J Med. 2014;371:2167-77. 
9. Yang JJ, Zhang XC, Su J, Xu CR, Zhou Q, Tian HX et al. Lung cancers with concomitant EGFR mutations and ALK rearrangements: diverse responses to EGFR-TKI and crizotinib in relation to diverse receptors phosphorylation. Clin Cancer Res. 2014;20:1383-92.

10. Zhou F, Zhou C. Targeted therapies for advanced patients with wild-type EGFR NSCLC: what's new and what's enough. Chin J Cancer. 2015;34. doi:10.1186/s40880-015-0036-4

11. Lovly CM, Shaw AT. Molecular pathways: resistance to kinase inhibitors and implications for therapeutic strategies. Clin Cancer Res. 2014;20:2249-56.

12. Xu X. Parallel phase 1 clinical trials in the US and in China: accelerating the test of avitinib in lung cancer as a novel inhibitor selectively targeting mutated EGFR and overcoming T790M-induced resistance. Chin J Cancer. 2015;34. doi:10.1186/s40880-015-0029-3
13. Fang BL, Mehran RJ, Heymach JV, Swisher SG. Predictive biomarkers in precision medicine and drug development against lung cancer. Chin J Cancer. 2015;34. doi:10.1186/s40880-015-0028-4

14. Yang JJ, Wu YL. Insight into early-phase trials for lung cancer in the United States. Chin J Cancer. 2015;34. doi:10.1186/s40880-015-0027-5

15. Yan L, Xu L. Early-phase Oncology Research Training (EFFORT) Program: a Hengrui-USCACA joint scholarship. Chin J Cancer. 2015;34. doi:10.1186/ s40880-015-0035-5

\section{Submit your next manuscript to BioMed Central} and take full advantage of:

- Convenient online submission

- Thorough peer review

- No space constraints or color figure charges

- Immediate publication on acceptance

- Inclusion in PubMed, CAS, Scopus and Google Scholar

- Research which is freely available for redistribution

Submit your manuscript at

www.biomedcentral.com/submit

C Biomed Central 